\title{
Efficiency of Sprayed Bentonite for Sealing of Fishpond Dams - Experimental Testing
}

\author{
Vaclav David ${ }^{1}$, Katerina Cernochova ${ }^{1,2}$, Jiri Stastka ${ }^{2}$ \\ ${ }^{1}$ Department of Landscape Water Conservation, Faculty of Civil Engineering, Czech Technical University in Prague \\ Thakurova 7, Prague 6, Czech Republic \\ vaclav.david@fsv.cvut.cz; katerina.cernochova@fsv.cvut.cz \\ ${ }^{2}$ DCentre of Experimental Geotechnics, Faculty of Civil Engineering, Czech Technical University in Prague \\ Thakurova 7, Prague 6, Czech Republic \\ jiri.stastka@fsv.cvut.cz;
}

\begin{abstract}
In this paper, the research focused on the efficiency evaluation of sprayed bentonite as a sealing layer of fishpond dams. The technology of sprayed bentonite was tested on a real scale model of an earthfill dam which was built as a $3 \mathrm{~m}$ wide section. The dam model was built with homogeneous earth material relatively permeable and equipped with an internal drain to monitor seepage flow. This was collected in a container equipped with an ultrasonic sensor for water level measurement purposes. The facility was also equipped with sensors for water level measurements in the reservoir upstream the dam. First, the seepage through the dam was measured without the sprayed bentonite-sealing layer. Then, the bentonite layer was sprayed on the upstream face of the dam by using a spraying technology based on the one used for dry process of sprayed concrete. This technology included a special nozzle and it was developed at Czech Technical University in Prague within the recent research. After the application of the sealing layer, the seepage through the dam was measured again and compared to the corresponding seepage without this sealing layer. The results indicate that the sealing bentonite layer lowers the seepage flow about four times compared to the solution without this sealing layer. Hence, this technology revealed efficiency with regard to the seepage flow reduction whereby will be further investigated.
\end{abstract}

Keywords: Earthfill dam; sprayed technology; bentonite; sealing, seepage.

\section{Introduction}

Dam breach of small water reservoirs or fishpond dams is the most common failure cause of these type of structures. The failures of fishpond dams are relatively frequent in Czech Republic due to the high number of structures of these type and also their advanced age. The average number of failures per year is in the decade ending 2004 was 10 [1]. Although the overtopping is the most common cause of these breaches occurrence, the internal erosion is also one other usual cause, not only in Czech Republic but also worldwide [2,3]. Accordingly, seepage should be carefully prevented or controlled in case of undesirable intensity occurrence. There are different methods to improve filtration stability of fishpond dams. One of the most used ones is the extension of dam body by a suitable material protected by stone material with gravel filtering layers as recommended by present standards for the construction of small water reservoirs - ČSN 752410 [4]. However, many fishponds are very old, becoming an integral part of the landscape over centuries. Many fishponds are therefore under some protection and it is not recommended to change the shape of the dam body. Thus, other technologies should be used to control seepage. Bentonite is a material with good sealing properties and it has been used for sealing fishponds in different ways worldwide over decades [5,6,7,8].

Sprayed technology is widely used in the field of concrete reinforcement $[9,10,11]$. However, it has not been applied yet in the application of bentonite materials. In the last years, Czech Technical University team has been developing a novel technology of sprayed bentonite. The use of this technology for the purpose of sealing earth-fill dams is one of the applications being considered. Both bentonite material and application nozzle are being developed within the research project "Conservation, reparations and monitoring of historical pond dams as our cultural heritage". The new nozzle and bentonite mixture have been being developed in the last years, and the complete technology, is now being tested on real scale dam models. The initial tests results are presented in this paper. The main advantage of this technology consists in the absence of 
needing to change the shape of the dam body when sealing is applied, which could be an advantage mainly in the case of protected old fishponds dams due to their historical value.

\section{Experimental setup}

The newly developed technology of sprayed bentonite was tested on a real scale dam model, which was built at the Centre of Experimental Geotechnics of the Czech Technical University in Prague.

\section{1. Dam model}

The dam model was built as a $3 \mathrm{~m}$ wide section surrounded in three sides by walls made of hollow concrete blocks reinforced by steel and filled by concrete. The dam body was built with permeable material (loamy sand) according to historical shapes as those from the $16^{\text {th }}$ century. These shapes are much narrower and steeper than the ones recommended by present guidelines. Slope of $1: 1\left(45^{\circ}\right)$ on both downstream and upstream faces were adopted. The dam body was equipped by a foot drain which assists collection of seepage water, allowing to monitor it. The model width of the dam body at the crest level was $3 \mathrm{~m}$. A scheme of the dam model is shown in Figure 1 and a real view is shown in Figure 2.

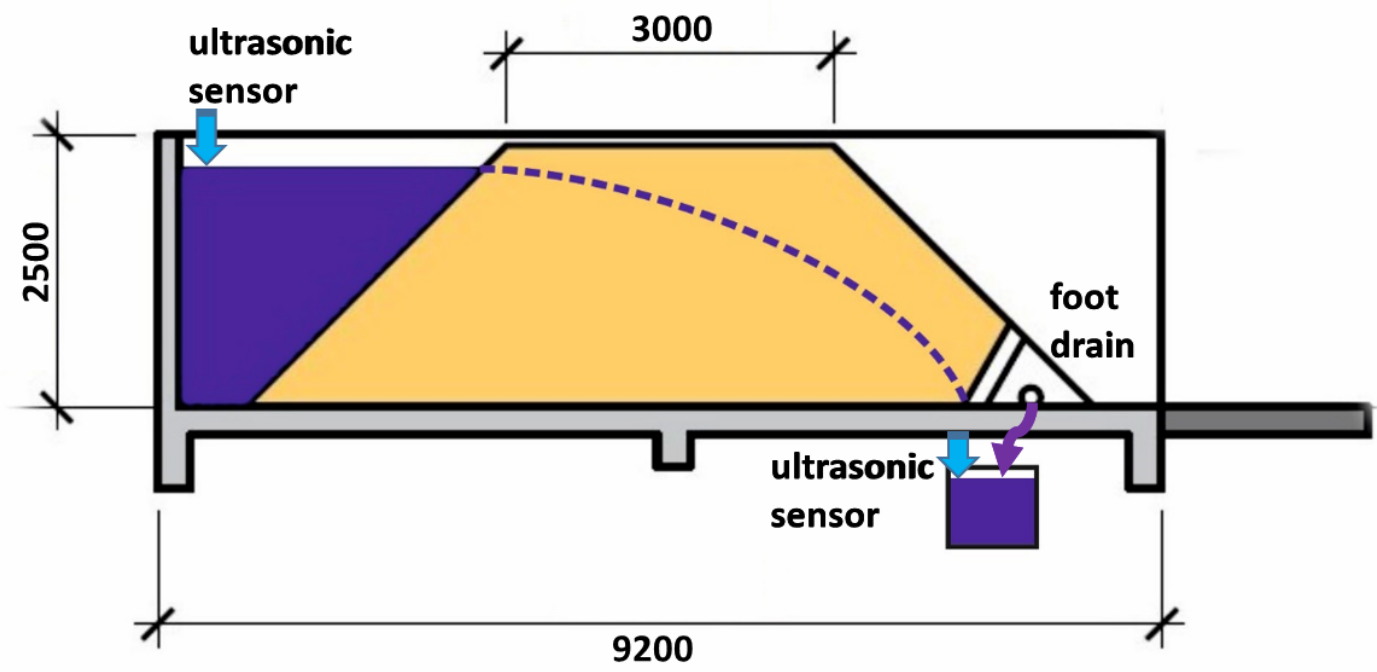

Fig. 1: Scheme of the experimental object with the dam model.

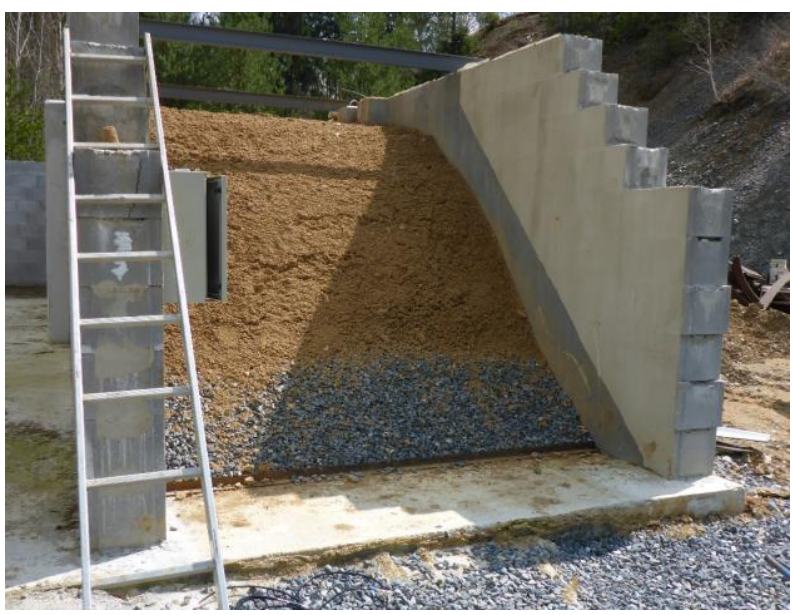

Fig. 2: View of the dam model. 


\section{2. Instrumentation}

The experimental model was equipped with water level and flow sensors to monitor the water levels in the pool and the the runoff in the foot drain. The drained flow was collected in a 300x400x320 mm container where the water level was measured with ultrasonic sensors (TURCK T30UXIA - measuring range 10-100 cm). The container was equipped with a a pump, for discharge purposes when the water level exceeds the $300 \mathrm{~mm}$. The pump was automatically activated using a a float switch and operated for $40 \mathrm{~s}$, during the dam measurements without the sealing, which was enough time to drain almost the whole container. Measurements on the dam model with the sealing, the pumping time was set shorter to prevent the pump ran out of water. The water level in the pool was measured using ultrasonic sensors (TURCK T30UXIC - measuring range $30-300 \mathrm{~cm}$ ). Measured data were recorded by the data logger DN4000. Additionally, climatic properties such as precipitation, temperature and air moisture content were measured to gather the climatic conditions during the experiment.

\section{Sprayed bentonite}

As mentioned in introduction, the bentonite material was developed specifically for the purpose of sealing fishpond dams as well as the nozzle with respect to its specific needs.

\section{1. Bentonite material}

The development of bentonite material to be applied using spray technology for sealing of fishpond dams runs since 2016. The developed granulated material named B75 REC MIX I is produced of bentonite B75 containing $75 \%$ of montmorillonite which was extracted at Cerny Vrch deposit. Stastka et al. [12] describe the production process of the granulated mixture. The mixture presents a good-fit of the Fuller's curve [13], which is very important as this curve describes ideal distribution of particle sizes. The ideal distribution then means that the space is optimally filled by particles, which leads to high density and low permeability. The grain size distribution is shown in Figure 3. The added water for the purposes of this experiment was set to $50 \mathrm{l} / \mathrm{h}$ according to results of previous tests.

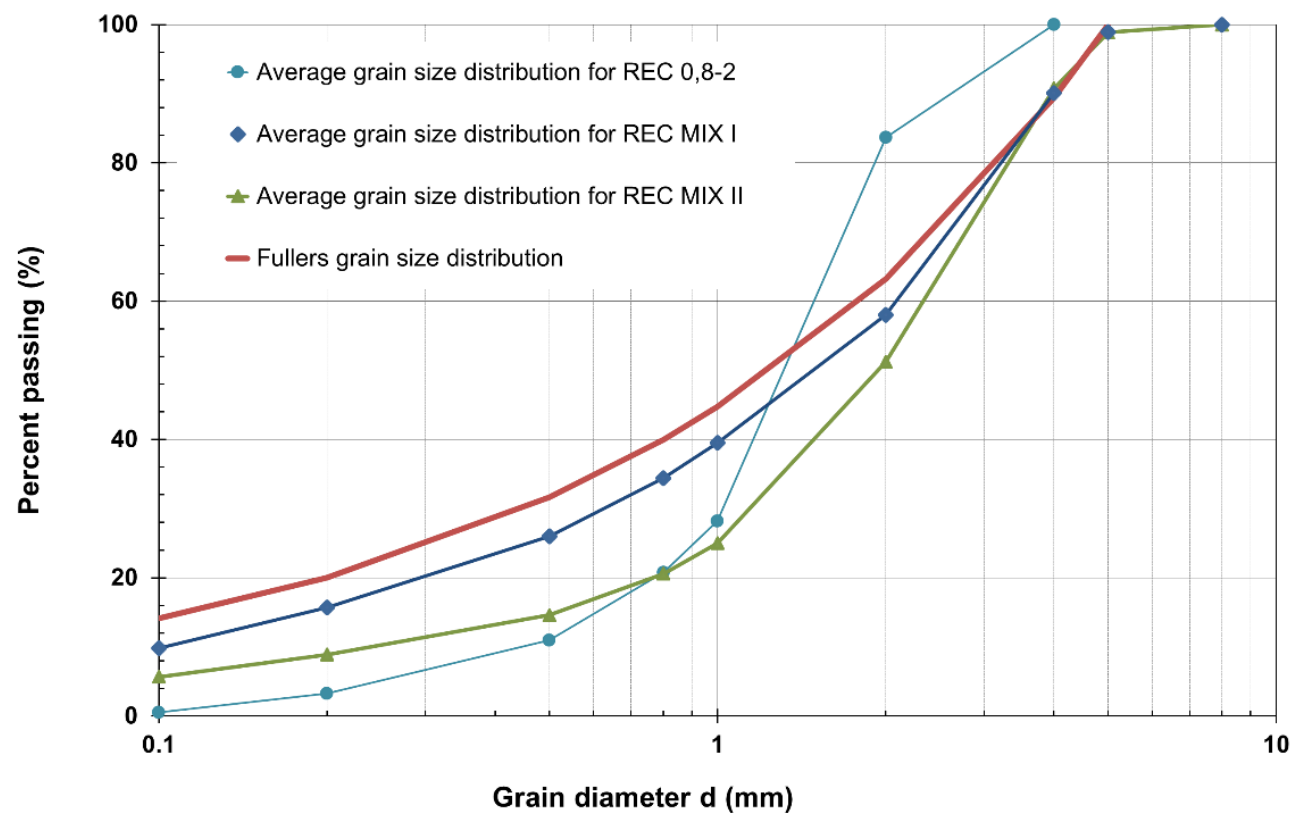

Fig. 3: Grain size distribution of used material B75 REC MIX I and its comparison with other available materials and the Fuller distribution (source [14]). 


\section{2. Spraying technology}

The spray technology used in the application of bentonite is based on the dry spray technology for sprayed concrete. consists on a first mixing of the granulated material with the compressed air in a dosing machine and a second addition water to the mixture in the nozzle. Stastka and David [14] describe in detail this technology. Although the nozzle is still being developed, it already provides a very good performance. The most recent version of the nozzle is shown in Figure

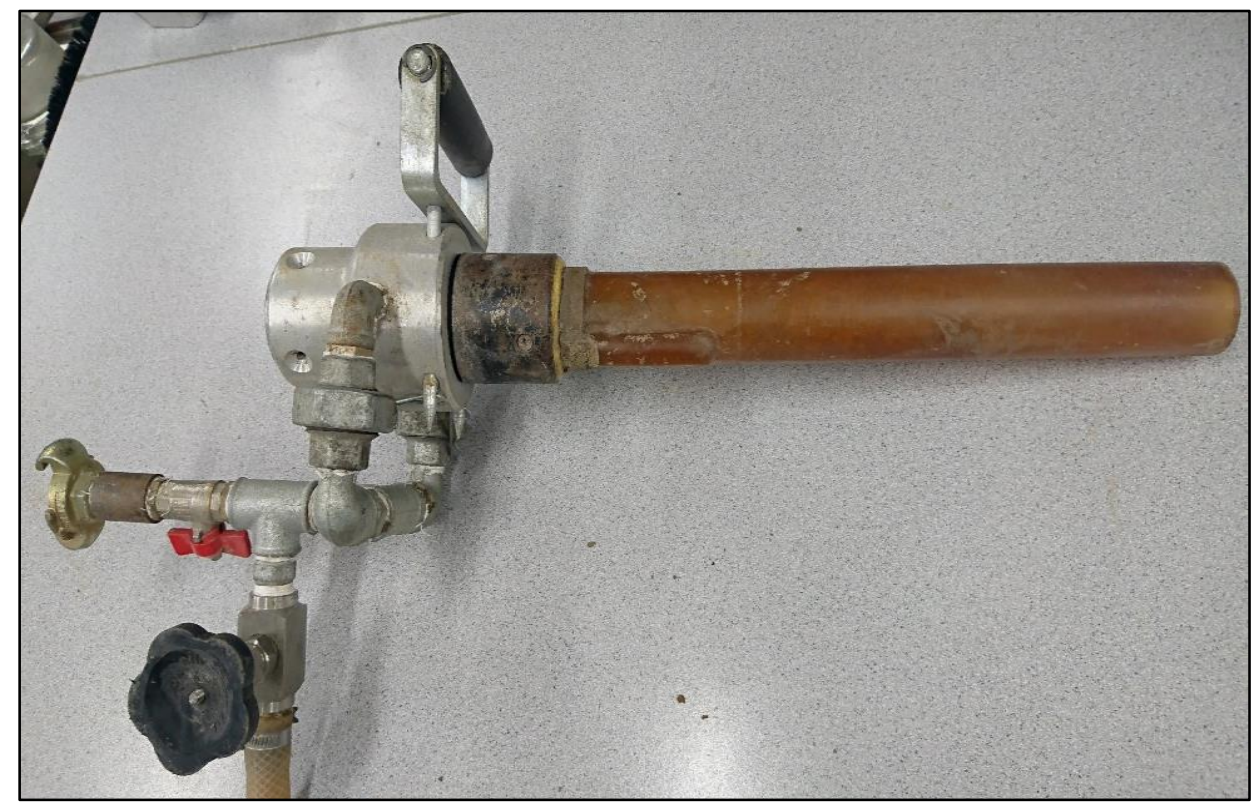

Fig. 4: Nozzle used for the application of bentonite on experimental dam.

\section{Experiment}

The efficiency of the sprayed bentonite was experimentally verified on the dam model by comparing seepage through the dam without and with the sealing bentonite layer. It consisted of the following steps:

- building the dam body;

- repeated filling and draining of the pool (done to consolidate the earth material and avoid distortion of the results by the changes in seepage sourcing from the compaction);

- measurement of seepage on the dam body without the sealing layer;

- application of bentonite sealing layer;

- experimental measurement of seepage on the dam body with the sealing layer.

Measurements started at the moment the pool was filled up to level $1.5 \mathrm{~m}$. Data was recorded with one-minute time step, which was considered appropriate to describe the process in detail. The experiment was conducted, in both cases, until the water level dropped to $0.5 \mathrm{~m}$.

Sealing layer was applied on the upstream face (see Figure 5) of the dam after the measurement of seepage on unsealed dam. It was checked whether the surface was not too dry as it could disturb the dam body causing a too dusty process. The thickness of the sealing layer was measured after application to assure that the minimum limits were satisfied in the full coverage of the sealed surface (variation of 3 to $5 \mathrm{~cm}$ were found).

During the experiments there was a problem with the power supply for the measurement apparatus causing the loss of some data. Another problem occurred with the ultrasonic sensors which are sensitive to warming up. It was detected by the analysis of the data from the experiment without sealing layer. The warming up of the ultrasonic sensors induced 
errors in the measured data, leading to the need to apply data filtrating. This problem was solved before running the experiment with sealing layer by installing an umbrella over the sensor, hence avoiding warming up due to direct incidence incidence of the sun. Last problem that should be mentioned was the pump destruction during the measurements on the dam dam with applied sealing layer. This caused loss of data at the later part of the experiment, from the water level $1.1 \mathrm{~m}$ in the in the pool.

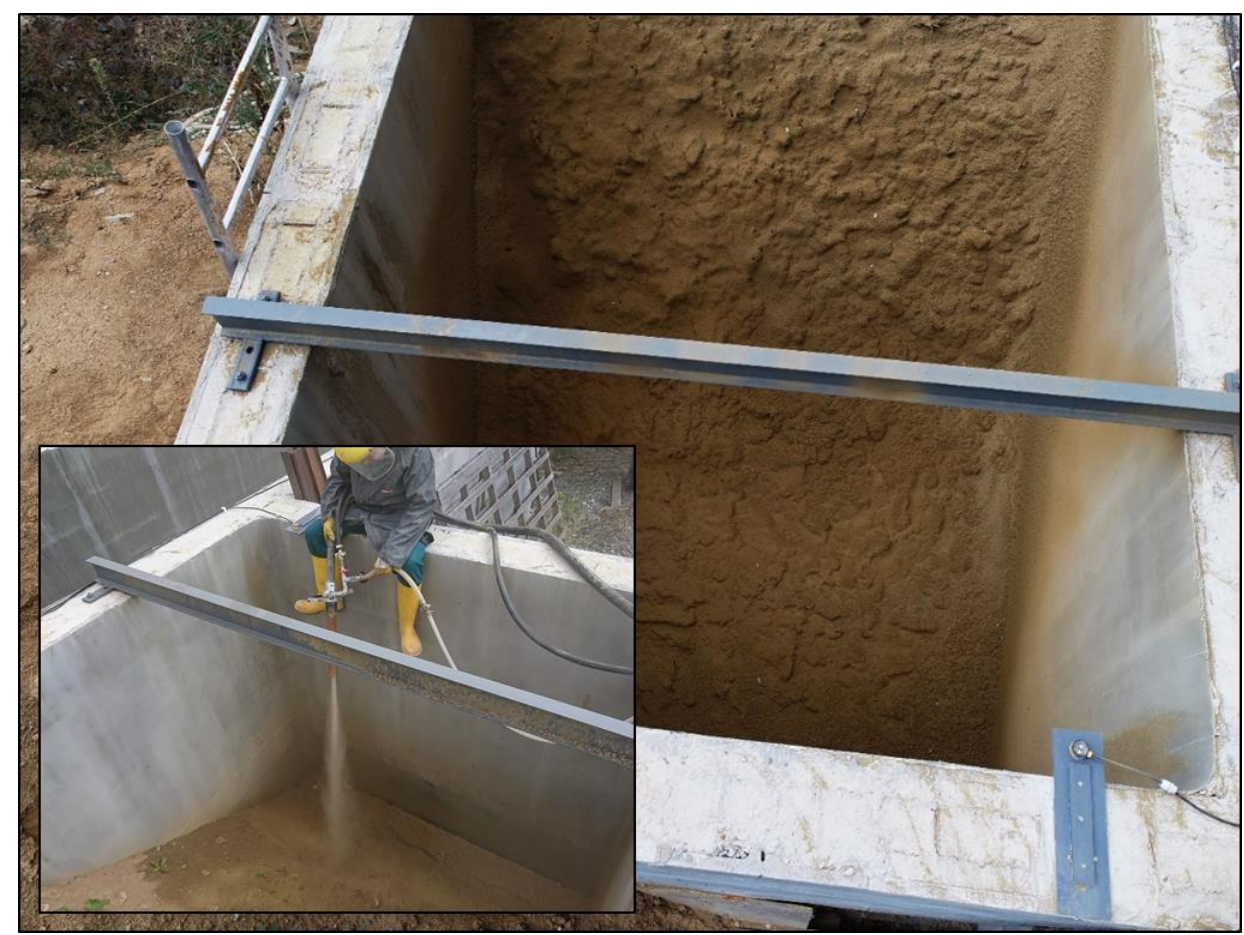

Fig. 5: Upstream face of the experimental dam with a bentonite layer applied and the application of bentonite (inside).

\section{Results}

Measured data was evaluated to get the time series of water level in the pool and corresponding runoff in the foot drain. Raw data was checked from the point of view of the accuracy and correctness. This was carried out in several ways. First, outliers were detected and removed from time series. These outliers were caused by warming up the ultrasonic sensors due to direct incidence of the sun. Second, the data affected by pumping procedure had to be removed as the exact time of pumping start and end could not be recorded and the pumped flow was not constant due to the water level fall in the collecting container. Hence, all data where the dropdown of water level in the container occurred was removed as well as the data corresponding to the local maximum or minimum, as it was more likely affected by the start or end of the collecting container drainage.

Filtered data was then used to calculate the runoff from the foot drain which was based on the known planar area of the container and on the time period between the data points. Filtered data used for further comparison of the seepage before and after the application of bentonite sealing layer, together with calculated values of runoff from the foot drain, are shown in Figures 6 and 7. In these figures, grey dots correspond to the water level in the pool while blue dots correspond to the water level in the collecting container. Orange dots show the runoff in the foot drain derived from the rate of water level rise in the container.

The main output of the experimental work is the comparison of seepage through the dam, before and after, the application of bentonite sealing layer. The comparison must be done for the same hydraulic heads in the pool which was sometimes difficult since some parts of the data series was lost. Figure 8 shows the plot of runoff values related to the hydraulic head 
for both states - before and after the application of sealing layer. There is only limited overlap between the data which is close to the water level in the pool about $1.2 \mathrm{~m}$. Within this overlap, the seepage through the dam with sealing layer (about $0.51 . \mathrm{min}^{-1}$ ) is about four times lower than the seepage without the sealing (about $2.01 . \mathrm{min}^{-1}$ ). This shows that the bentonite material presents very good sealing properties.

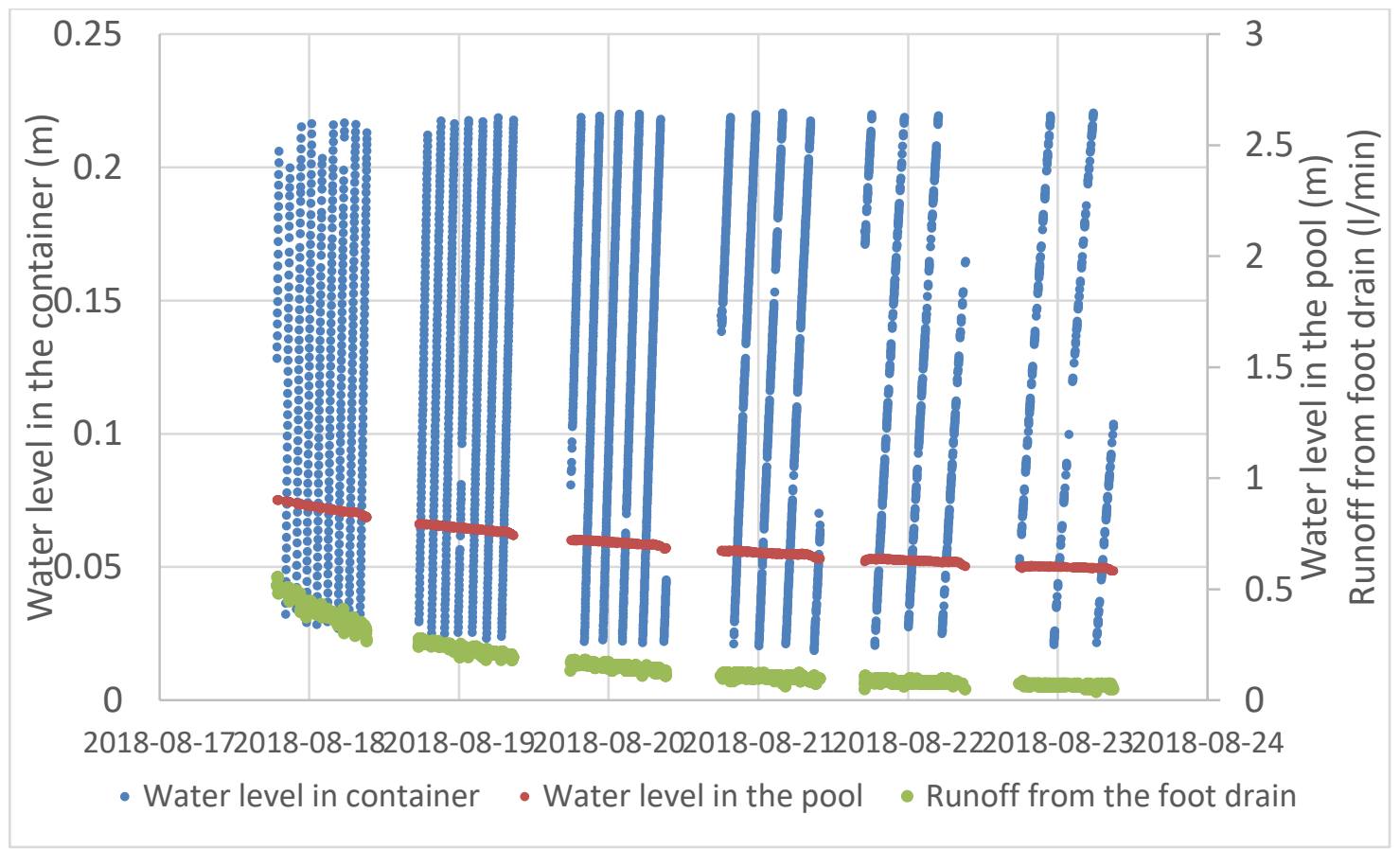

Fig. 6: Filtered data measured on the experimental dam without the sealing layer).

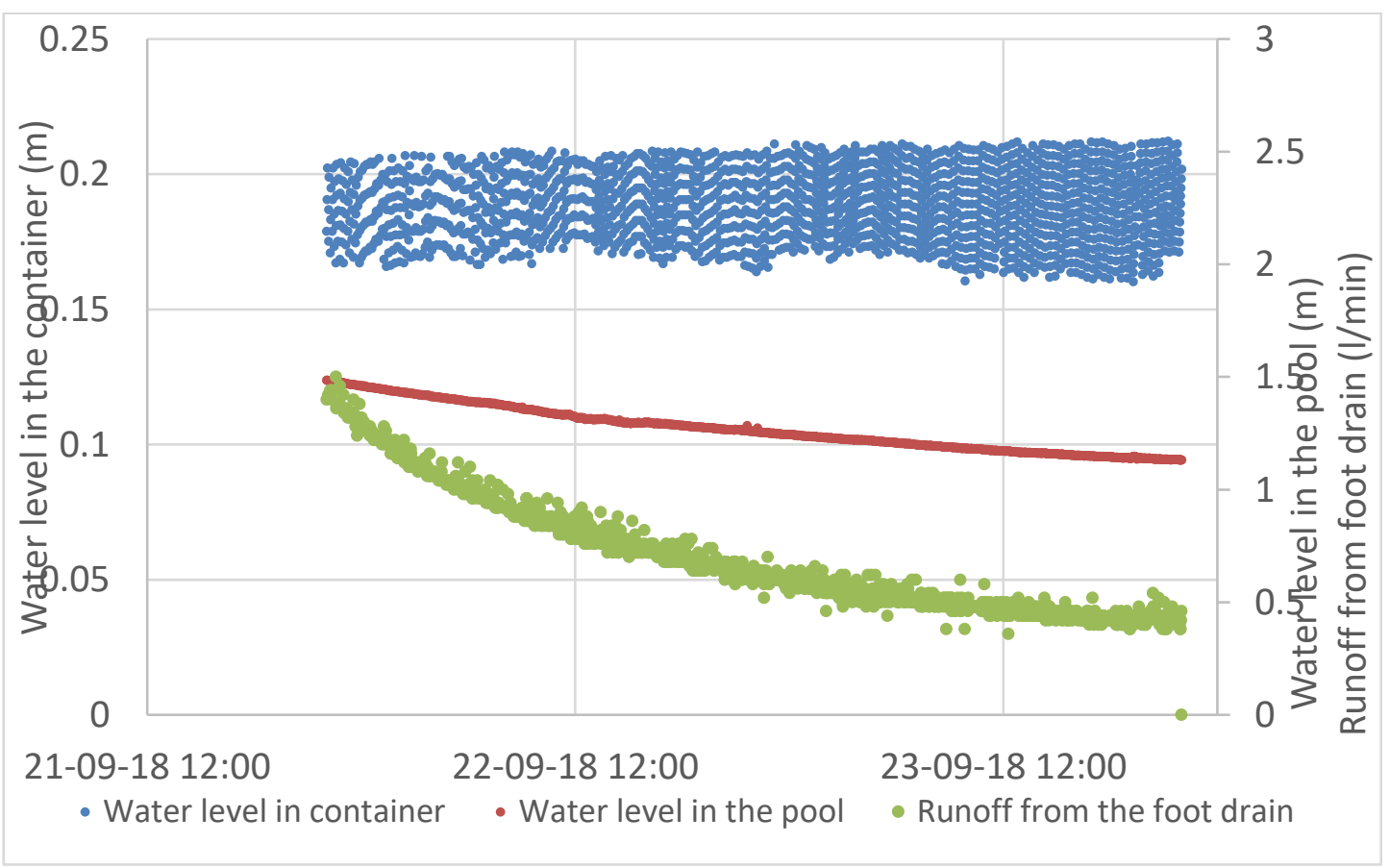

Fig. 7: Filtered data measured on the experimental dam with the sealing layer. 
Hydraulic head vs. foot drain runoff

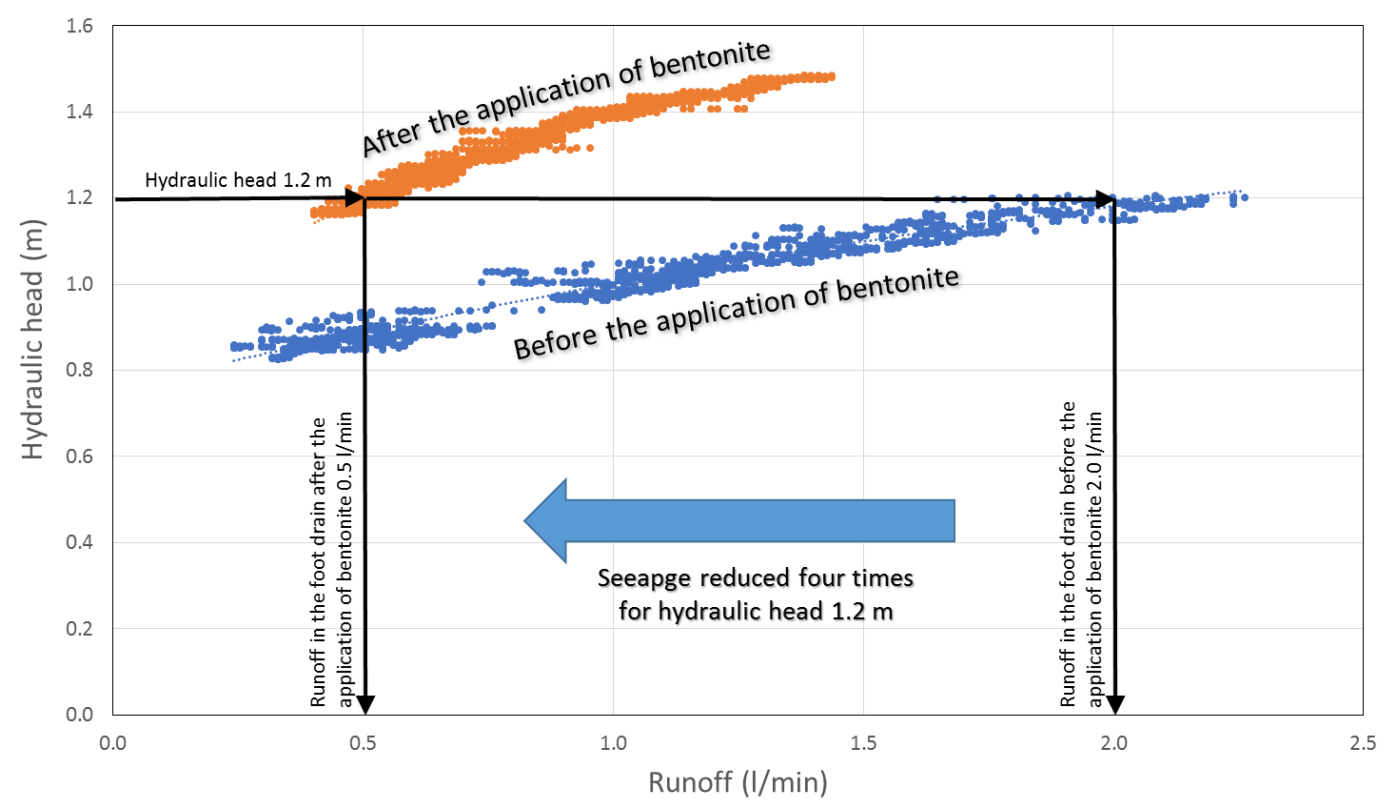

Fig. 8: Seepage through the experimental dam before and after the application of bentonite sealing layer.

\section{Conclusion}

In this paper, the initial testing of sprayed bentonite technology for sealing of fishpond dams on a real scale model is presented. The experimental testing of the technology proves very good sealing properties of used material. The application of bentonite layer on the experimental dam resulted in about four-time lower seepage through the experimental dam. Hence, the technology seems to be useful for sealing fishpond dams and prevents seepage increasing through the dam, which could help to avoid the failures due to internal erosion. These are the first results of the initial testing of this technology. In addition, assessment that is more detailed could have been done if the data was complete. Several lessons were learned from this experiment, namely related to the experimental work and monitoring apparatus that will help to prevent data losses in the next experiments. First, it was noticed that the ultrasonic sensors could be significantly affected by the warming up due to direct incidence of the sun. This problem was already solved by the protecting the sensors with umbrellas. Second, the collecting container drainage with a pump can fail causing the loss of important data. Hence, the experimental setup was modified so that the drainage in further experiments is ensured by a siphon equipped with an electromagnetic valve operated directly with the data logger based on the instantaneous water level in container.

In 2019, further experiments will be carried out to prove the sealing properties of developed technology. These experiments will be done on the experimental dam with steep slopes which is presented in this paper and on the experimental dam having slopes corresponding to current standard guidelines. These experiments will be followed by the research focused on the stability of sealing layer and its protection.

\section{Acknowledgements}

The research presented in this paper was funded within a project no. DG16P02M036 „Conservation, reparations and monitoring of historical pond dams as our cultural heritage" granted by Ministry of Culture of the Czech Republic through the Development of National and Cultural Identity Programme NAKI II. The support is highly acknowledged. 


\section{References}

[1] J. Riha, "Comments on failures of small dams in the Czech Republic during historical flood events," in Long-term benefits and performance of dams: Proceedings of the 13th Conference of the British Dam Society and the ICOLD European Club meeting held at the University of Kent, Canterbury, UK from 22 to 26 June 2004. Thomas Telford Publishing, 2004, pp. 597-608.

[2] L. M. Zhang, Y. Xu and J. S. Jia, “Analysis of earth dam failures: A database approach,” Georisk, vol. 3, no. 3, pp. 184-189, 2009.

[3] O. E. Omofunmi, J. G. Kolo, A. S. Oladipo, P. D. Diabana and A.S. Ojo, "A review on effects and control of seepage throught earth-fill dam," Current Journal of Applied Science and Technology, vol. 22, no. 5, pp. 1-11, 2017.

[4] UNMZ. ČSN 752410 Small water reservoirs [Czech Technical Standard]. Prague: Úřad pro technickou normalizaci, metrologii a státní zkušebictví, 2011, p. 48.

[5] I. A. F. Laing and R. G. Pepper, "Sealing farm dams," Journal of the Department of Agriculture, Western Australia, Series 4, vol. 17, no. 2, pp. 52-57, 1976.

[6] N. Sima and A. Harsulescu, "The use of bentonites for sealing earth dams," Bulletin of the International Association of Engineering Geology-Bulletin de l'Association Internationale de Géologie de l'Ingénieur, vol. 20, no. 1, pp. 222226, 1979.

[7] R. Flores-Berrones, M. Ramírez-Reynaga and E. J. Macari, "Internal erosion and rehabilitation of an earth-rock dam," Journal of Geotechnical and Geoenvironmental Engineering, vol. 137, no. 2, pp. 150-160, 2010.

[8] M. Kociánová, R. Drochytka and V. Černý, "Technology of remediation of embankment dams by optimal grout," Procedia Engineering, vol. 151, pp. 257-264, 2016.

[9] R. T. L. Allen, S. C. Edwards and D. N. Shaw (Eds.). Repair of concrete structures. CRC Press, pp. $228,1992$.

[10] A. Thomas, A. Sprayed concrete lined tunnels. CRC Press, pp. 274, 2008.

[11] S. Mindess (Ed.). Developments in the Formulation and Reinforcement of Concrete. Elsevier, pp. 308, 2014.

[12] J. Stastka, V. David, and K. Cernochova, "Preparation for the Final Testing of the Sprayed Bentonite Sealing Layer of a Pond Dam," in E3S Web of Conferences, vol. 65, pp. 02008 EDP Sciences, 2018.

[13] W. B. Fuller and S. E. Thompson, "The laws of proportioning concrete," Asian Journal of Civil Engineering Transport, pp. 67-143, 1907.

[14] J. Stastka and V. David, "The Testing of a Sprayed Bentonite Sealing Layer," in Multidisciplinary Digital Publishing Institute Proceedings, vol. 2, no. 11, pp. 666, 2018. 